\title{
Study of 2D Laser Beam Imprinting using an Asymmetric Channel Cut Crystal
}

John Seely, Charles Brown, and Glenn Holland

Space Science Division, Naval Research Laboratory

Code 7674, Washington DC 20375-5352

Tel. 202-767-3529, john.seely@nrl.navy.mil

\section{Contents:}

1. Design of the Asymmetric Channel Cut Crystal

2. Fabrication of the Silicon Crystal

3. Experimental X-Ray Data

\section{Design of the Asymmetric Channel Cut Crystal}

The asymmetric channel cut crystal was designed to record the perturbation of a silicon crystal by non-uniformities in an OMEGA laser beam. The instrument design was composed of three parts: (1) silicon crystal, (2) instrument support structure, including the nose cono, and (3) time-resolving detector, such as a streak camera or framing camera.

Critical to the experiment was the use of crystals of a high degree of perfection. as it would be difficult to separate crystal defects from perturbations imprinted by the Omega laser. Only a few materials are available with the required degree of perfection, Germanium and Silicon being two. Initial data indicated that Germanium was the only crystal capable of reflecting $X$-rays at the asymmetric cut angles required, and supplies of very high quality Ge were scarce and extremely expensive. Subse guent calculations for Si 220 indicated that it too could be fabricated into a asymmetric cut crystal with good reflecting properties. Fortunately, high quality Si crystals are abundant and moderately priced.
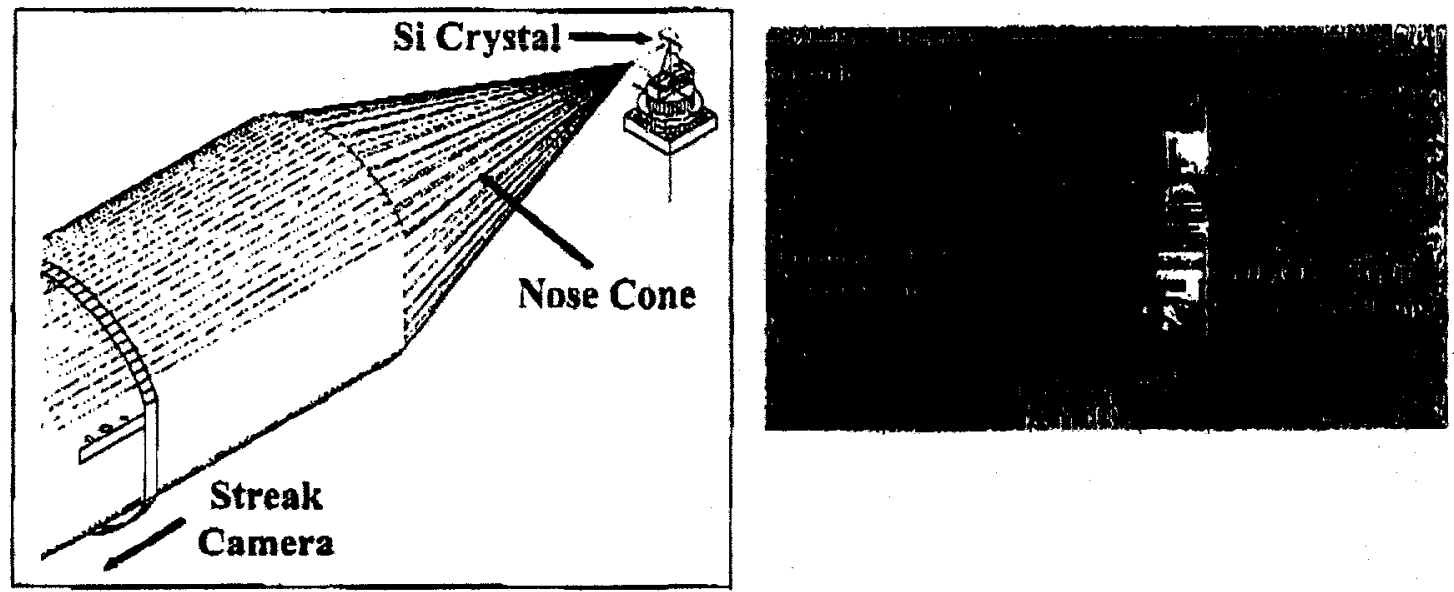


\section{DISCLAIMER}

This report was prepared as an account of work sponsored by an agency of the United States Government. Neither the United States Government nor any agency thereof, nor any of their employees, make any warranty, express or implied, or assumes any legal liability or responsibility for the accuracy, completeness, or usefulness of any information, apparatus, product, or process disclosed, or represents that its use would not infringe privately owned rights. Reference herein to any specific commercial product, process, or service by trade name, trademark, manufacturer, or otherwise does not necessarily constitute or imply its endorsement, recommendation, or favoring by the United States Government or any agency thereof. The views and opinions of authors expressed herein do not necessarily state or reflect those of the United States Government or any agency thereof. 


\section{DISCLAIMER}

Portions of this document may be illegible in electronic image products. Images are produced from the best available original document. 
The silicon crystal was composed of three parts: (1) a post with a small dot of titanium that served as the $x$-ray source, (2) a flat surface cut parallel to the Si 220 planes that diffracted the $x$-ray radiation from the source, and (3) a surface cut obliquely to the 220 planes that expanded the $x$-ray beam, and reflected toward the detector.

One or more OMEGA beams were to be incident on the Ti dot and create a hot Ti plasma. The OMEGA irradiation was designed to primarily create the helium-like Ti ionization stage. The resulting piasma is an intense source of the heliurnlike $T$ i resonance line emission with a wavelength of $2.62 \AA(4.75 \mathrm{keV})$. The crystal surfaces were cut to diffract the $2.62 \AA$ radiation from the silicon 220 crystal lattice planes at a Bragg angle of $42.3^{\circ}$.

The diffracted beam is incident on the obliquely cut surface. An OMEGA beam is also incident on this surface and penurbs the crystal lattice. Owing to perturbations of the lattice spacing by non-uniformities in the OMEGA beam, the diffracted $x$-ray beam has spatial and temporal variations that are recorded by the time-gated detector.

An optical facet was polished on the base $f$ the crystal to facilitate alignment. Its normal is

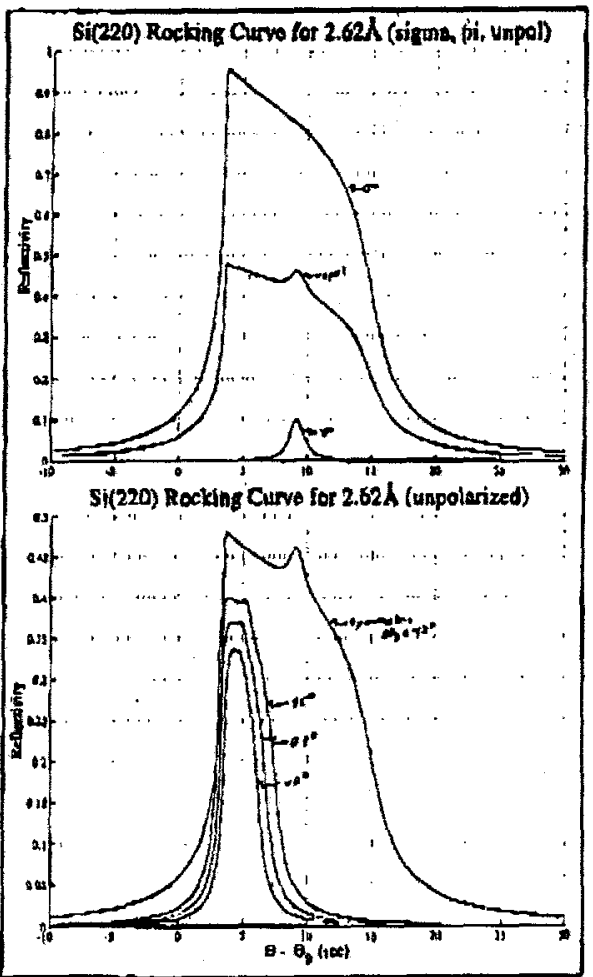
parallel to the diffraction direction of the $x$-rays from the obliquely cut facet. A HeNe or other laser beam propagared from the detector location should retro-reflect onto itself from this facet when the crystal orientation is correct.

\section{Fabrication of the Silicon Crystal}

The procedure for cutting the silicon crystal was designed to utilize a saw blade with the smallest available width. This resulred in the smallest possible size and mass of the resulting cut crystal and the minimal debris in the planned OMEGA experiment. The crystal was mounted on a precision rotary table beneath a diamond saw and oriented for repeated saw cuts as shown in the following Figure. The crystal was oriented so that the 220 planes were horizontal in the Figure. The small block of silicon at the left in the Figure was left as a convenient mounting surface for a titanium target. A microdot of $\mathrm{Ti}$ can be precisely located on this block so that the Bragg conditions are met for the Ti Helike lines to reflect from the parallel (top) and oblique (right) cut leaves of the asymmetric cut channel. 


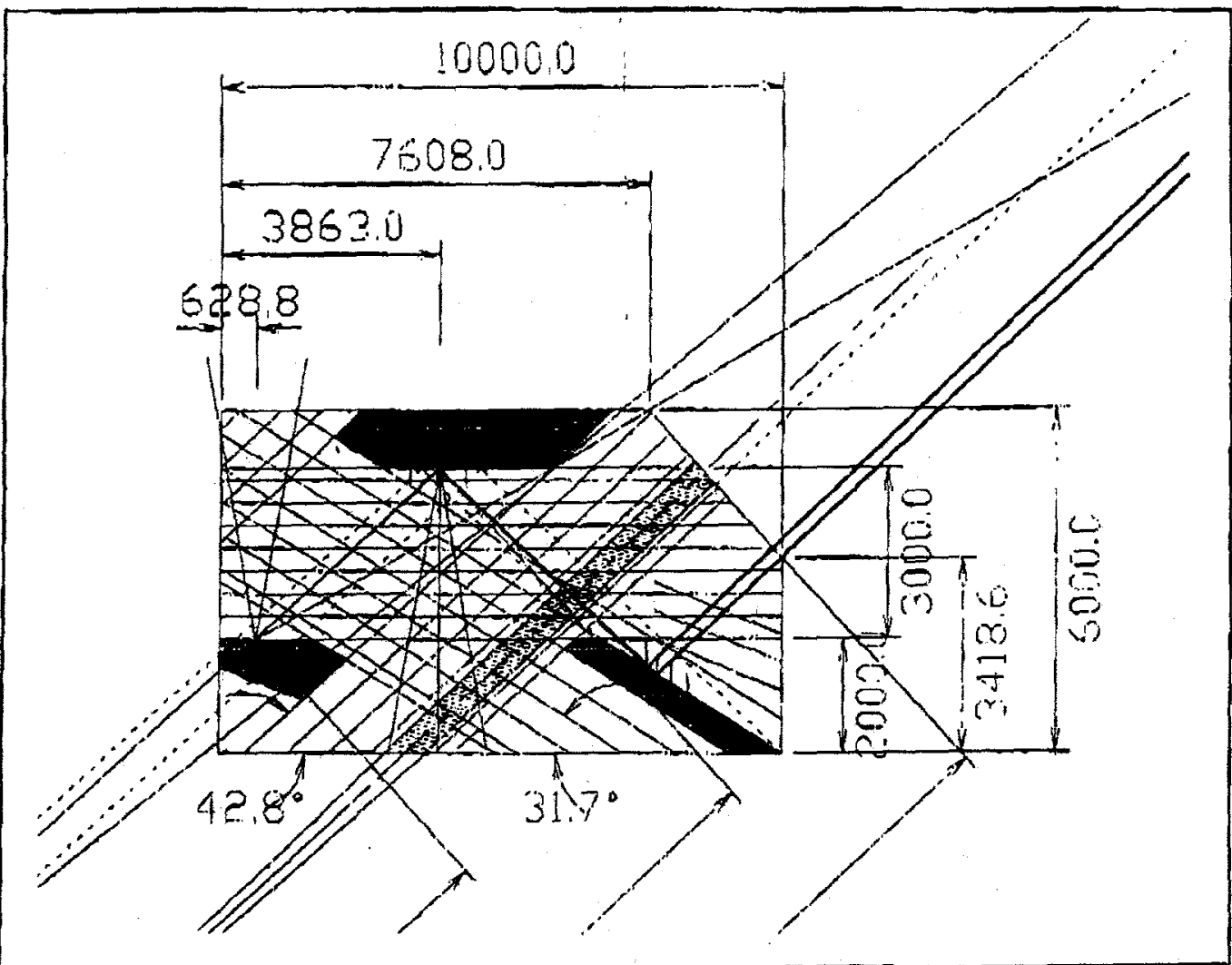

Magnification occurs in the asymmetric cut crystal at the oblique surface. While the crystal planes are still horizontal, the beam intersects the surface at an angle

$$
\theta=\theta_{\text {Bragg }}-\theta_{\text {cut }}
$$

Where $\theta_{\text {cut }}$ is the angle between the crystal planes and the saw cut. The magnification is

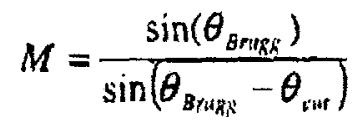

Three views of the fabricated crystal are shown. The reflecting surfaces of the silicon crystal were etched to remove material damaged in the machining operation..
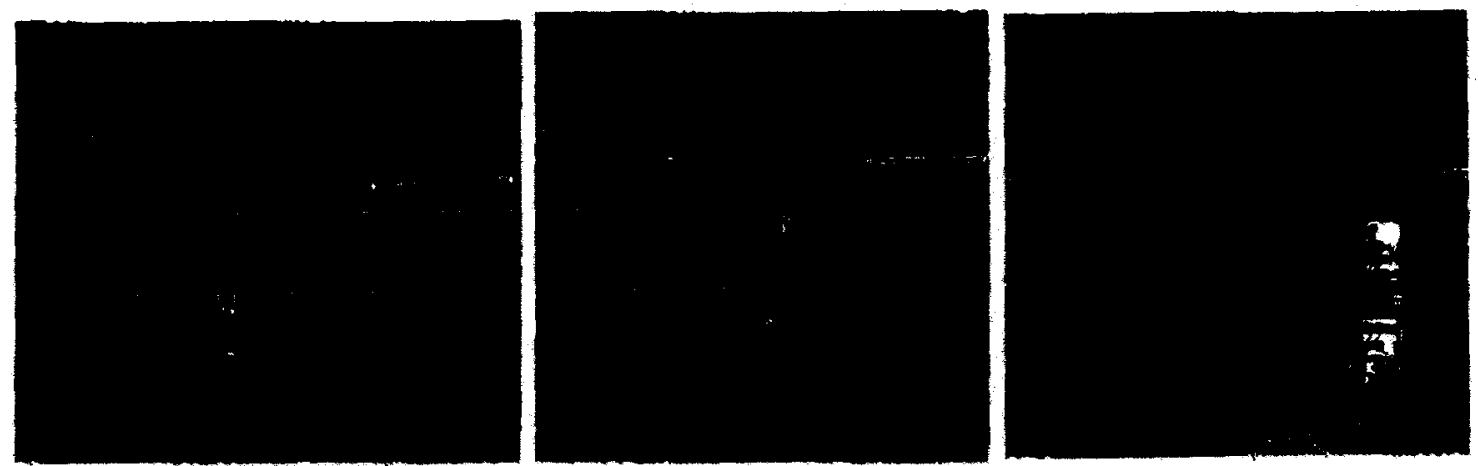


\section{Experimental X-Ray Data}

Experimental data were recorded using a laboratory source of Copper $\mathrm{K} \alpha$ radiation in second order. This experiment served to validate the performance of the asymmetric channel cut crystal. In particular, the calculation of the bearn expanding potential of the asymmetric cut silicon 220 crystal was verified for the first time. Although the Bragg angles were slightly different ( $53.3 \mathrm{deg}$ for $\mathrm{CuK} \alpha$ vs, $42.8 \mathrm{deg}$ for Ti He-like), appreciable magnification in one dimension is still seen when the diffracted beam is compared to the direct beam. Since the $\mathrm{Cu} x$-ray tube was relatively far from the first leaf of the channel cut crystal, the $x$-ray beam is nearly parallel in this dimension.
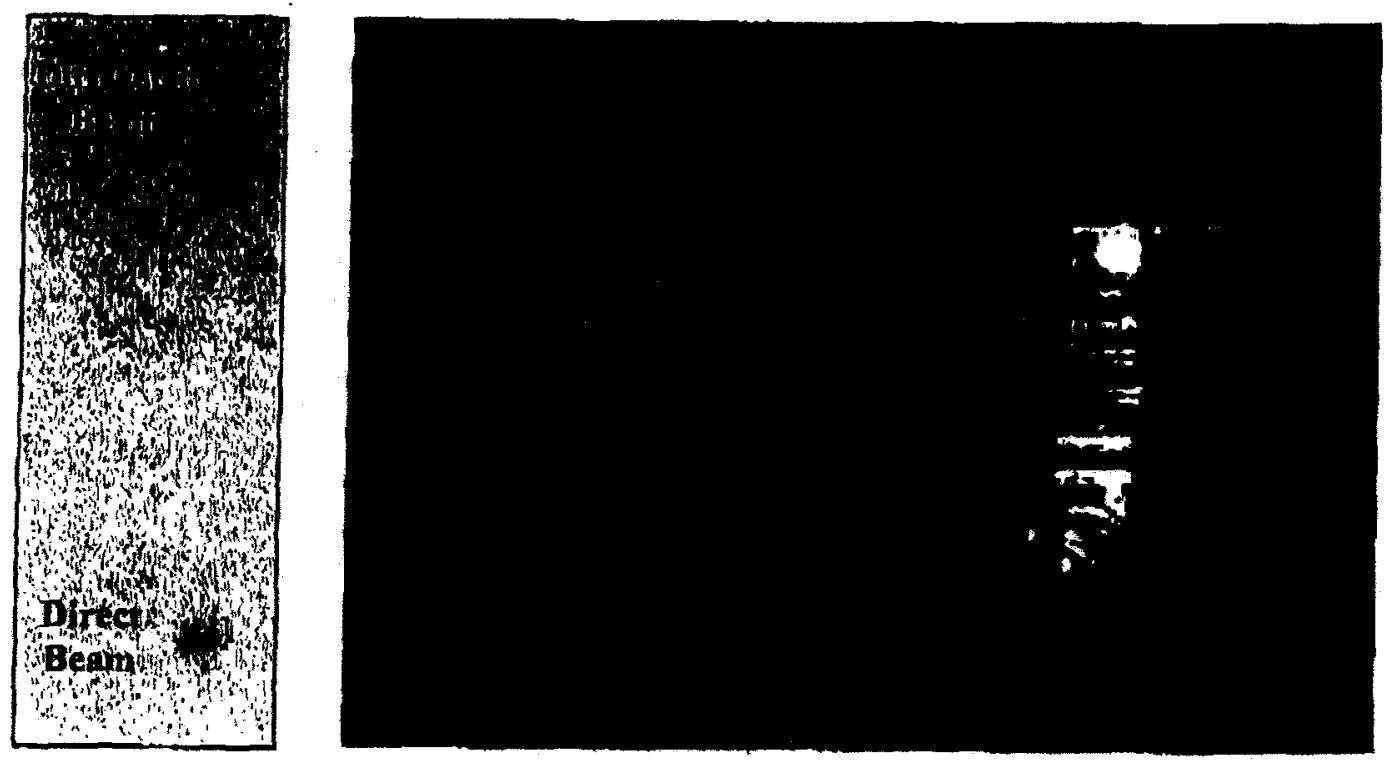

Although the asymmetric channel cut crystal was successfully fabricated and tested, scientists at the Laboratory for Laser Energetics believed that the debris generated during the planned OMEGA shots might have a detrimental effect on the OMEGA target chamber and optics. The plans for the OMEGA shots were therefore suspended. 